\title{
QUANDO A VOZ DO POVO É A VOZ DE DEUS \\ A PROCISSÃO DA PARÓQUIA DE SÃO DIMAS NA SEMANA SANTA EM SÃO JOSÉ DOS CAMPOS
}

Paulo Roxo Barja

A procissão promovida pela Catedral da Paróquia de São Dimas é realizada em São José dos Campos (SP) há mais de 50 anos, configurando-se como um dos pontos altos da comemoração da Semana Santa nessa cidade - evento que supera a contraposição frequentemente estabelecida entre a religiosidade popular das ruas e a religião formal da Igreja católica. Em 2010, a procissão foi inovadora: as etapas da Paixão de Cristo foram pela primeira vez apresentadas na forma de trechos de um filme americano, num telão móvel, ficando a tradicional representação teatral restrita ao início do drama, ainda na igreja, e ao momento da crucificação, em praça pública. Embora represente uma tentativa de modernização, com a introdução de aparato tecnológico, a novidade dividiu opiniões: boa parte dos participantes ainda prefere o calor da representação ao vivo. [Abstract on page 244]

\section{RELIGIOSIDADE POPULAR, SEMANA SANTA, SANTOS POPULARES, VALE DO PARAÍBA.}

BARJA, Paulo Roxo. Quando a voz do povo é a voz de Deus: a procissão da paróquia de São Dimas na Semana Santa em São José dos Campos. Textos escolhidos de cultura e arte populares, Rio de Janeiro, v.7, n.1, p. 93-99, mai. 2010. 


\section{INTRODUÇÃO}

A expressão "cultura popular" representa, como já afirma Chartier (1995), uma categoria definida no meio erudito, surgindo justamente como contraposição à cultura erudita, acadêmica. Por analogia, à medida que se multiplicam os estudos sobre religiosidade popular, surge o impulso de perguntar se isso faz sentido: haveria por acaso uma religiosidade erudita? Na elaboração do presente artigo não é essa (falsa) questão que interessa. O que nos motiva é simplesmente apresentar o exemplo de uma circunstância em que se observa na verdade a fusão de prática religiosa mais tradicional, autenticada pela Igreja católica (a procissão da Semana Santa), com sentimento (e prática) mais próximo do que se tem convencionado chamar de religiosidade popular. Mas, afinal, como definir religiosidade popular? Concordamos com Câmara Neto em seu estudo sobre o contraponto entre religiosidade popular e catolicismo "oficial", quando atesta "a dificuldade de enquadrar de modo definitivo a religiosidade popular em um modelo fechado" (CÂMARA NETO, 2003). No entanto, o mesmo autor apresenta pistas importantes para a compreensão dessa religiosidade, ao afirmar que "as manifestações de religiosidade popular independem de classe social", apresentando "independência da hierarquia eclesiástica (...), materializada em uma explosão quase íntima ao 'sagrado', humanizando-o, sentindo-o próximo, testando-o e sentindo sua força” (CÂMARA NETO, 2002).

Assim, a religiosidade popular pode ser entendida como uma vivência religiosa não doutrinária, mas espontânea e alicerçada em relação humanizada, afetiva mesmo, com o sagrado. Manifesta-se, por exemplo, na devoção aos ditos "santos populares", aqueles que se tornam santos na visão do povo, independentemente de ter ou não passado pelas instâncias necessárias à santificação oficial da Igreja católica, obtendo reconhecimento do Vaticano. O Vale do Paraíba, no Estado de São Paulo, é em particular região pródiga em exemplos desses santos populares, que são motivo de romarias e mote de festas em diversas cidades da região, sendo extenso o calendário vale-paraibano de festas religiosas (PELLEGRINI FILHO, 1985; SEBRAE, 2008). É importante ressaltar, porém, que não se pode falar em "concorrência" entre os chamados santos populares e aqueles oficialmente reconhecidos pela Igreja. Em geral, ocorre justamente o contrário: quem pede ajuda a Nossa Senhora de Aparecida é muitas vezes, por exemplo, o mesmo peregrino que deposita um pedido e uma vela junto ao túmulo da andarilha Maria Peregrina, no Cemitério de Santana, em São José dos Campos.

Trataremos aqui, em particular, da procissão da Semana Santa promovida pela comunidade da Paróquia de São Dimas, em São José dos Campos, cujo breve histórico será apresentado neste trabalho. Antes disso, no entanto, é preciso contextualizar a devoção popular nessa região, o que faremos a seguir.

\section{A DEVOÇÃO POPULAR NO VALE DO PARAÍBA}

Trata-se de fenômeno rico e variado, com diversos peregrinos adotados como santos pelo povo, como é o caso da andarilha Maria Peregrina, cujo túmulo recebe dia- 
riamente a visita de devotos que muitas vezes ali depositam velas acesas. Em geral, esse tipo de devoção nasce da admiração do povo por pessoas de condição muitas vezes humilde e que ao longo da vida passaram por grande sofrimento, mostrando resignação.

Um exemplo é o do padre Rodolfo Komórek, polonês que chegou ao Brasil em 1924, passando por diferentes regiões antes de se mudar para São José dos Campos, a fim de cumprir tratamento de combate à tuberculose. Contrariando as recomendações médicas de repouso absoluto, padre Rodolfo passou a peregrinar diariamente pela cidade, além de rezar missas na capela do Sanatório Vicentina Aranha.

Com o tempo, surgiram boatos de curas milagrosas efetuadas pelo padre que ao falecer (em 1949) já congregava muitos devotos. Há quase 50 anos foi aberto processo para sua beatificação, que, entretanto, ainda aguarda formalização. Enquanto isso, no entanto, os devotos multiplicam-se, a ponto de a cidade de São José dos Campos abrigar o Museu e Relicário do Padre Rodolfo Komórek (MILANI, 2005).

De modo geral, exemplos de santos populares joseenses, como o padre Komórek e Maria Peregrina (transformada, aliás, em tema de peça teatral montada com grande sucesso no Vale do Paraíba) mostram que, embora um dos critérios tradicionais da Igreja católica para a beatificação de alguém seja a observação das virtudes apresentadas pelo "candidato", no caso da devoção popular adquire especial importância a identificação com a figura do santo, seja pelo sofrimento resignado, seja pela origem humilde ou mesmo por suas fraquezas. Nesse sentido, cabe citar o trabalho de José Rogério Lopes (2003), que observa "distinção clara entre os santos venerados eclesiasticamente e aqueles venerados nos segmentos populares".

Como bem destaca Bráulio Nascimento (2005), na cultura popular os santos são tratados "com uma familiaridade típica das relações humanas, que pode incluir censuras e castigos". Quebra-se assim a ideia de que os santos estariam "acima das outras pessoas". Os santos populares, definidos como aqueles que são alvo da devoção popular (independentemente de serem aceitos oficialmente ou não pela Igreja), são justamente aqueles dos quais se pode dizer que são "gente como a gente".

Nesse contexto, não é de estranhar a importância, em São José dos Campos, da Catedral da Paróquia de São Dimas, a única catedral do mundo dedicada ao chamado Bom Ladrão, crucificado junto com Jesus Cristo. Vejamos a seguir um pouco da história desse santo.

\section{SÃO DIMAS: O LADRÃO QUE VIROU SANTO}

São Dimas é considerado um dos primeiros santos da Igreja católica - seu culto data dos primeiros séculos da era cristã. Bandido de origem egípcia, pagão, Dimas teria abrigado a Sagrada Família no deserto, protegendo-a até a entrada no Egito.

Devido a sua origem, naturalmente são Dimas é considerado o santo dos pecadores, sejam eles bêbados, jogadores ou ladrões. Segundo o Evangelho de são Lucas, ao arrepender-se de seus pecados e reconhecer em Jesus o Filho de Deus, Dimas pede a Cristo 
que se lembre dele ao entrar no Reino dos Céus, ao que Jesus Ihe responde: "em verdade te digo que hoje estarás comigo no Paraíso".

\section{A PARÓQUIA DE SÃO DIMAS: BREVE HISTÓRICO}

Com a instalação do Centro Técnico Aeroespacial (CTA), em 1950, e a inauguração da Rodovia Presidente Dutra, no ano seguinte, a cidade de São José dos Campos inicia forte processo de industrialização. Observando o crescimento da cidade, o bispo de Taubaté, dom Francisco Borja do Amaral, decreta em 1951 a criação da Paróquia de São Dimas em território joseense.

A primeira procissão (e festa) de são Dimas ocorreu em 8 de abril de 1951, saindo da paróquia (provisoriamente instalada na Vila Ema, na Capela do Menino Jesus de Praga) em direção ao local do futuro templo, inaugurado dois anos depois. Com o aumento da população e do número de devotos, em 1970 iniciou-se a construção da nova (e atual) Igreja de São Dimas, com capacidade para mais de mil pessoas, inaugurada em 1981.

Em 2009, a catedral recebeu um fragmento da Relíquia do Patíbulo do Bom Ladrão (são Dimas), guardada na Basílica de Santa Cruz em Jerusalém. Esse fragmento foi entronizado em celebração solene da abertura da Novena de São Dimas, que culminou com a procissão pelas ruas da paróquia no dia 26 de abril de 2009, sendo seguida por missa e almoço festivo da comunidade (CATEDRAL DE SÃO DIMAS, 2009).

\section{A PROCISSÃO DA SEMANA SANTA}

Como em várias outras cidades do Vale do Paraíba, também em São José dos Campos a Semana Santa é comemorada com uma série de festividades promovidas por diferentes igrejas, muitas vezes de grande porte. Nesse contexto, merece destaque a procissão da Semana Santa organizada pela comunidade da Paróquia de São Dimas. Trata-se de evento tradicional, realizado há cerca de 60 anos, do qual participam não apenas os membros da comunidade da paróquia, como também um grande número de moradores da cidade que não frequentam habitualmente a igreja.

O evento se inicia com uma encenação dentro da catedral, que apesar de suas dimensões não comporta a totalidade do grande público presente já no início da celebração. Assim, boa parte das pessoas fica do lado de fora da igreja, aguardando o início da procissão propriamente dita.

Ao longo da procissão, são apresentadas ao público as diversas cenas da Paixão de Cristo, até que se chega à praça, onde é representada a cena da crucificação, seguida da ressurreição de Cristo.

A encenação é basicamente montada com a participação de membros da comunidade, não necessariamente habituados ao "fazer artístico". E cabe aqui destacar um paradoxo: enquanto na igreja a representação assume ares de espetáculo, à medida que as pessoas saem da igreja e a procissão se inicia, ganha corpo na rua a vivência religiosa. 
Num primeiro momento, há os inevitáveis cumprimentos à família e amigos (um dos soldados abre um sorriso e, entre feliz e orgulhoso, acena para os pais na saída da igreja, por exemplo). Mas a caminhada é longa. E é ao longo do percurso que se "opera o milagre" da construção de uma cumplicidade que envolve o público em geral, abrindo espaço para a vivência de uma religiosidade popular, já que na procissão os protagonistas não são apenas as figuras sagradas, mas também o povo.

A que atribuir isso? Em primeiro lugar, o simples fato de caminhar juntos já estabelece cumplicidade natural, ainda que muitas vezes silenciosa (o silêncio pode ser, aliás, fator agregador, no contexto da meditação e da experiência religiosa).

Depois, há a questão das velas, cujo simbolismo (conexão entre o mortal e o sobrenatural) já foi discutido por Toninho Macedo no prefácio da obra Maria Peregrina (MELO, 1992). Esse autor ressalta que o uso ritualístico da vela (e do fogo, de modo mais geral) é bem anterior ao próprio catolicismo, sendo costume pagão encontrado no Império Romano e na Grécia Antiga, por exemplo. Assim, a vela é elemento importante na devoção popular - e não poderia ser diferente na procissão da Semana Santa.

Fato é que andar por cerca de três quilômetros na rua, à noite, empunhando uma vela acesa, não é tarefa das mais simples, como se evidencia logo no início da procissão (um parênteses: pode ser essa a explicação para a crença popular no município de São Sebastião, que recomenda a quem deseja casar que caminhe, com uma vela acesa, atrás da imagem de São Gonçalo na procissão dedicada ao padroeiro da cidade. Se a vela ficar acesa até o final da procissão, o casamento acontecerá em breve).

Desse modo, na procissão em São José dos Campos, durante o caminhar da multidão, há sempre uma vela se apagando. E sempre, por outro lado, alguém próximo, com uma vela acesa e boa vontade, prontificando-se a "compartilhar o fogo" com o desconhecido tornado irmão pela experiência em curso. A dificuldade desperta a solidariedade, e a beleza do gesto (bem como da procissão em si) passa pela constatação da total ausência de barreiras entre os participantes.

A discussão frequentemente colocada quanto à dualidade de São José dos Campos, cidade espremida entre as definições (sempre redutoras) de "caipira" e "tecnológica/industrial" perde sentido na procissão. Cientistas, professores universitários e pesquisadores caminham lado a lado com pessoas de origem e ocupação humildes.

Tradicionalmente, a procissão é interrompida em diversos pontos para a encenação dos passos da Paixão de Cristo, pelo grupo de atores que fez a representação inicial na igreja. Na procissão de 2010, no entanto, houve mudança significativa: a representação teatral, à frente do público, foi trocada pela inserção de um conjunto de projetor e telão móveis para visualização de cenas do filme $A$ paixão de Cristo, em produção americana, legendada. A cada parada, um narrador apresenta brevemente a próxima cena.

A novidade, como não poderia deixar de ser, dividiu opiniões. A estratégia facilita, e muito, o trabalho dos atores, que podem dirigir-se diretamente à praça onde representarão as cenas finais do drama, sem o desgaste da peregrinação. No entanto, alguns 
participantes levantam dúvidas sobre a eficácia do método, uma vez que as pessoas que caminham mais atrás na procissão podem ter dificuldade na visualização das cenas - e é necessário ler as legendas, uma vez que o filme é falado em inglês. Fica no ar a sensação de que a maioria das pessoas preferiria ter de volta a representação ao vivo durante todo o percurso. E por que isso? Justamente porque a vivência da religiosidade popular requer proximidade, intimidade com o sagrado. $\mathrm{O}$ ator brasileiro, ainda que amador, é mais próximo, mais "real" que o ator do filme americano.

Logo após a encenação, qualquer dúvida que se possa ter sobre o caráter popular do evento é dirimida: diversas pessoas, principalmente crianças e jovens, correm para tirar fotografias junto do ator que faz o papel de Jesus Cristo. A manifestação é obviamente espontânea e por isso mesmo significativa. É bom estar perto de Jesus Cristo.

Ao final do encontro, as últimas palavras dos celebrantes são de recomendação simples e direta ao público: pede-se que as pessoas não deixem nenhum lixo no caminho. "É bom deixar a praça ainda mais limpa do que estava quando aqui chegamos." As pessoas compreendem e respeitam o aviso e vão, aos poucos, tomando seus rumos. Vão tranquilas e, pelo menos no semblante, mais "limpas" do que estavam quando as encontramos.

\section{A PROPOSTA (PARADOXAL) DE INOVAR A TRADIÇÃO}

O rápido e acentuado desenvolvimento econômico e populacional nas últimas décadas é fenômeno marcante de São José dos Campos. Em 1960, a cidade apresentava menos de 80 mil habitantes, número que praticamente dobrou uma década depois atualmente, a população joseense supera os 600 mil habitantes. Esse crescimento acelerado explica a coexistência de aspectos caipiras e tecnológicos/industriais na cidade. Conforme já observamos, essa coexistência é verificada claramente durante a procissão da Paróquia de São Dimas na Semana Santa.

A tentativa de modernização da procissão, com a substituição da representação teatral de passagens bíblicas pela apresentação de trechos de filme num telão móvel, reafirma e acentua a busca do convívio entre a tradição e a modernidade. No entanto, aqui estamos no campo da vivência religiosa popular; no campo de um ritual católico, que cresce e se fortalece com a repetição. E a repetição é um dos mecanismos estruturais básicos de funcionamento dos rituais, que segundo Rodolpho (2004) apresentam em sua essência caráter continuísta, mas não devem ser considerados "simples formalidades".

Desse modo, não chega a ser surpreendente a sensação de que os participantes da procissão reagem ao telão com certo estranhamento. Na verdade, em nenhum momento durante a procissão é verbalizada qualquer censura à proposta inovadora, mas é possível ouvir, aqui e ali, o comentário de que "ano passado ainda foi melhor". Parte do público se mostra reticente quanto à inovação tecnológica. Talvez a mais significativa afirmação a respeito venha do ator que representa Jesus Cristo na encenação teatral. Em tese, trata-se do maior favorecido com a mudança na procissão, por ter sido poupado do trabalho de carregar a cruz por cerca de três quilômetros. No entanto, logo após o even- 
to, ele afirma que, "se ano que vem quiserem", aceita voltar a carregar a cruz durante o percurso. E diz isso com a convicção característica da fé popular. Podemos concluir dizendo que, nesse caso, na voz do "filho de Deus" na representação ecoa a voz do povo.

\section{REFERÊNCIAS BIBLIOGRÁFICAS}

CÂMARA NETO, I. A. Diálogos sobre religiosidade popular. Ciências Humanas Unitau, v.8, n.2, 2002.

. Religiosidade popular e catolicismo oficial: o eterno contraponto. Ciências Humanas Unitau, v.9, n.1, 2003.

CATEDRAL DE SÃO DIMAS. Nossa História, 2009. Disponível em http://www.catedralsaodimas.org.br/conteudos.php?act=ler\&id=13 (acessado em 02/05/2010).

CHARTIER, R. Cultura popular: revisitando um conceito historiográfico. Estudos Históricos, V.8, n.16, 1995: 179-192.

LOPES, J. R. Imagens e devoções no catolicismo brasileiro. Fundamentos metodológicos e perspectivas de investigações. Revista de Estudos da Religião - Rever, v.3, 2003: 1-29.

MACEDO, T. Santos do Altar do Povo. In MELO, J.B.M. Maria Peregrina. Cadernos de Folclore n.6, São José dos Campos: Fundação Cultural Cassiano Ricardo, 1992.

MELO, Benedito Jose Batista de. Maria Peregrina. São Jose dos Campos: Fundação Cultural Cassiano Ricardo, 1992.

MILANI, T.E. História de Padre Rodolfo Komórek é atrativo de museu, 2005. Disponível em http://jornal.valeparaibano.com.br/2005/03/01/viv01/historia.html (acessado em 10/05/2010).

NASCIMENTO, B. O sagrado e o profano nos contos populares. Textos Escolhidos de Cultura e Arte Populares, v.2, n.2, 2005: 77-89.

PELLEGRINI FILHO, A. Folclore paulista: documentário \& calendário. São Paulo: Cortez Editora/Secretaria de Estado da Cultura, 1985.

RODOLPHO, A. L. Rituais, ritos de passagem e de iniciação: uma revisão da bibliografia antropológica. Estudos Teológicos, v.44, n.2, 2004: 138-146.

SEBRAE. Circuito Turístico Mantiqueira. São Paulo: Sebrae, 2008.

Paulo Roxo Barja é músico e físico, doutor em Ciências pela Unicamp (2000), pós-doutorado pela USP (2001), docente-pesquisador da Univap desde 2002. Criador do blog Cordéis Joseenses (cordeisjoseenses.blogspot.com), atualmente divide seu tempo entre a docência, a pesquisa e as atividades artísticas. 
